\title{
Pt and $\mathrm{Hf}$ Additions to NiAl Bond Coats and Their Effect on the Lifetime of Thermal Barrier Coatings
}

\author{
J.A Nesbitt ${ }^{1}$, B. Gleeson ${ }^{2}$, D. Sordelet ${ }^{2}$ and C.A. Barrett ${ }^{1}$ \\ ${ }^{1}$ NASA Glenn Research Center, Cleveland, OH 44135, USA \\ ${ }^{2}$ DOE Ames Laboratory, Ames, IA 50011-3020, USA
}

Keywords: TBC's, thermal barrier coatings, Ni-aluminides, bond coats

\begin{abstract}
The lifetimes of thermal barrier coatings (TBC's) with various NiAlPt(HfZr) bond coats were determined by cyclic oxidation testing at $1163^{\circ} \mathrm{C}\left(2125^{\circ} \mathrm{F}\right)$. The bond coats were sprayed from powders by low pressure plasma spraying onto Renè N5 superalloy substrates. Yttria stabilized zirconia (8YSZ) top coats were applied by air plasma spraying. Surprisingly, there was not a strong correlation between TBC lifetime and $\mathrm{Pt}$ or $\mathrm{Hf}$ content although $\mathrm{Zr}$ additions decreased lifetimes. TBC failure morphologies and bond coat microstructures were examined and are discussed with respect to the bond coat compositions.
\end{abstract}

\section{Introduction}

Thermal barrier coatings (TBC's) are commonly used in the hot section of aero gas turbine engines and provide oxidation as well as thermal protection [1,2]. TBC's provide thermal protection via an outer ceramic layer usually consisting of $\mathrm{ZrO}_{2}-8 \mathrm{wt} . \% \mathrm{Y}_{2} \mathrm{O}_{3}$ (8YSZ). This ceramic layer, or top coat, is typically applied by either air plasma spraying (APS) or by electron beam-physical vapor deposition $[2,3]$. TBC's afford oxidation protection by use of a metallic bond coat positioned between the substrate and the 8YSZ top coat. The bond coat is typically either an MCrAlY coating (where M refers to $\mathrm{Ni}$ and/or $\mathrm{Co}$ ) or a $\mathrm{Ni}$ aluminide coating. Incorporating $\mathrm{Pt}$ into the aluminide coating produces the so-called "Pt-modified aluminide coatings" which result in improved oxidation and hot corrosion protection $[4,5]$. It is well known that the presence of $\mathrm{Pt}$ in Ni-aluminide bond coats also increases the lifetime of TBC's (the TBC lifetime is generally taken as the service time prior to spallation of the ceramic top coat). However, the reason for the improvement caused by Pt, and the optimum level of $\mathrm{Pt}$, is still unclear. More recently, the addition of small amounts of $\mathrm{Hf}$ to Pt-modified aluminide coatings has also been shown to increase TBC lifetimes [6]. The addition of reactive elements (e.g., $\mathrm{Hf}, \mathrm{Zr}$ and $\mathrm{Y})$ to $(\mathrm{Ni}, \mathrm{Co}) \mathrm{CrAl}$ and $\mathrm{NiAl}$ alloys has long been known to improve the adherence of the alumina scale which grows on the surface of these alloys [7]. The purpose of the present work was to examine further the effect on $\mathrm{TBC}$ lifetime of $\mathrm{Pt}, \mathrm{Hf}$ and $\mathrm{Zr}$ additions to $\mathrm{NiAl}$ bond coats. To eliminate the compositional inhomogeneities of diffusion aluminide coatings, the bond coats were fabricated by low pressure plasma spraying pre-alloyed $\mathrm{NiAlPt}(\mathrm{Hf}, \mathrm{Zr})$ powders.

\section{Experimental Procedure}

Five NiAlPt(Hf,Zr) compositions were prealloyed and cast in ingot form prior to powder fabrication by gas atomization. A binary $\mathrm{NiAl}$ powder and a $\mathrm{NiAl}(\mathrm{Zr})$ powder, previously procured, were used as baseline compositions without Pt. Bond coat designations and powder compositions are given in Table 1 where it can be seen that the actual and nominal compositions are quite close. The one notable exception is that Ni50Al14PtZr and Ni50Al14PtHfZr show significant Zr pickup, presumably from the zirconia molds used in prealloying the alloys. The powders were sprayed by low pressure plasma spraying (LPPS) onto Renè N5 superalloy disks $2.54 \mathrm{~cm}(1 \mathrm{in})$ in diameter by $0.32 \mathrm{~cm}(0.125 \mathrm{in})$ thick. Bond coat thickness was nominally $100 \mu \mathrm{m}$ (0.004 in). An 8YSZ top coat, nominally $178 \mu \mathrm{m}(0.007$ in) was deposited over the bond coat by APS. 
Table 1 Powder Compositions

\begin{tabular}{|c|c|c|c|c|c|c|c|c|c|c|c|}
\hline & Alloy & Actual & Nominal & Actual & Nominal & Actual & Nomina & Actual & Nominal & Actual & Nominal \\
\hline & Designations & \multicolumn{2}{|c|}{$\mathrm{Ni}[$ at.\%] } & \multicolumn{2}{|c|}{$\mathrm{Al}$ [at.\%] } & \multicolumn{2}{|c|}{$\mathrm{Pt}$ [at.\%] } & \multicolumn{2}{|c|}{$\mathrm{Hf}$ [at.\%] } & \multicolumn{2}{|c|}{$\mathrm{Zr}$ [at.\%] } \\
\hline 1 & $\mathrm{Ni50Al}$ & 49.10 & 50.00 & 50.85 & 50.00 & 0.00 & 0.00 & 0.01 & 0.00 & 0.00 & 0.00 \\
\hline 2 & $\mathrm{Ni}-50 \mathrm{Al} 7 \mathrm{Pt}$ & 43.08 & 43.00 & 49.67 & 50.00 & 7.17 & 7.00 & 0.01 & 0.00 & 0.05 & 0.00 \\
\hline 3 & Ni-50Al14PtZr & 36.54 & 36.00 & 48.86 & 50.00 & 13.97 & 14.00 & 0.02 & 0.00 & 0.58 & 0.00 \\
\hline 4 & Ni-42Al7Pt & 49.80 & 51.00 & 42.94 & 42.00 & 7.18 & 7.00 & 0.01 & 0.00 & 0.03 & 0.00 \\
\hline 5 & Ni50Al7PtHf & 42.96 & 42.80 & 49.64 & 50.00 & 7.17 & 7.00 & 0.15 & 0.20 & 0.05 & 0.00 \\
\hline 6 & Ni50Al14PtHfZr & 37.15 & 35.80 & 48.69 & 50.00 & 13.73 & 14.00 & 0.15 & 0.20 & 0.25 & 0.00 \\
\hline 7 & $\mathrm{Ni50AIZr}$ & 50.98 & 51.70 & 48.67 & 48.20 & 0.00 & 0.00 & 0.02 & 0.00 & 0.10 & 0.10 \\
\hline
\end{tabular}

Samples were thermal cycle tested in automated cyclic oxidation rigs. Each cycle consisted of 45 minutes at $1163^{\circ} \mathrm{C}\left(2125^{\circ} \mathrm{F}\right)$ followed by a minimum cooling in ambient air for 15 minutes which cooled the samples to approximately $40^{\circ} \mathrm{C}$. Samples were periodically inspected (the minimum inspection interval was 10 cycles) for top coat delamination or spalling. Failure was determined as a minimum of $20 \%$ top coat delamination or spalling. Three samples of each bond coat were tested. Following testing, fracture surfaces at the bond coat/top coat interface were examined by scanning electron microscopy (SEM) and energy dispersive spectroscopy (EDS) and polished cross sections were examined by optical and SEM-EDS. X-ray diffraction of the bond coat surface where the top coat had delaminated was also performed. Because of space constraints, post test analysis results for $\mathrm{Ni50Al}$ and Ni50Al14PtZr will be emphasized.

\section{Results and Discussion}

Examples of typical failure morphologies are shown in Fig 1. Fig 1a shows a typical delamination which usually initiated at an edge. Figs $1 \mathrm{~b}, \mathrm{c}$ show that the delaminations can spread rapidly until the entire top coat delaminates from the bond coat. The cycles to failure are shown in Fig 2. As shown, the TBC lifetimes for five of the bond coats are very similar with shorter lifetimes for Ni50Al14PtZr and Ni50AlZr. It is surprising that the binary Ni50Al bond coat shows an average TBC lifetime somewhat greater than that for the bond coats containing Pt or reactive elements.
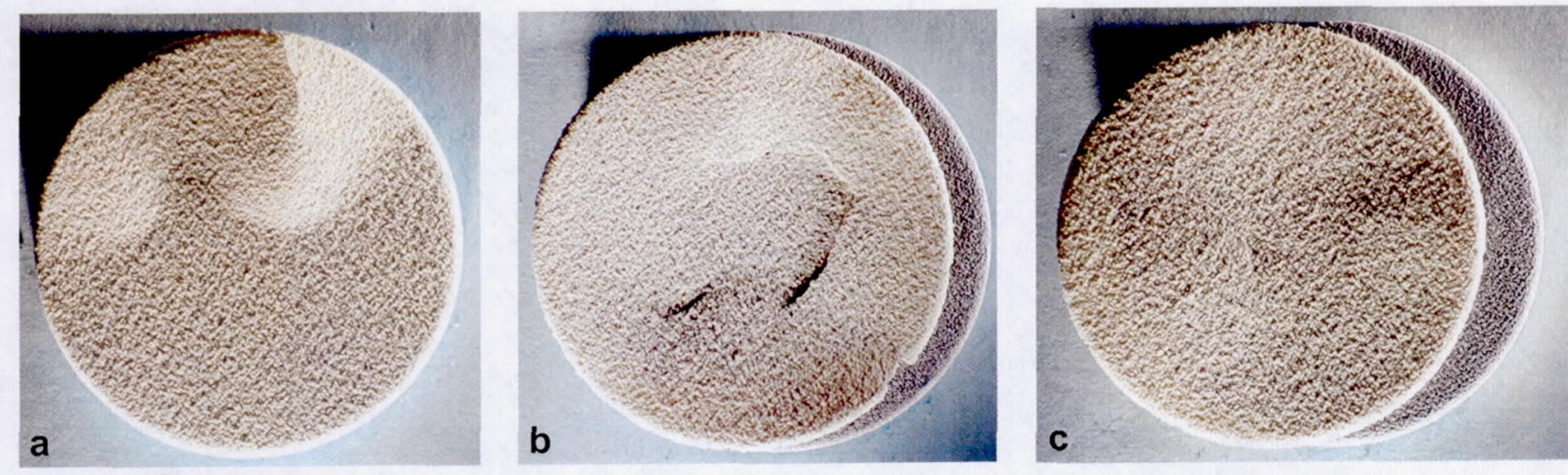

Figure 1 Macrographs of tested samples at failure showing buckling and total delamination of the ceramic top coat. (a) Ni50Al, 160 cycles, (b) Ni50Al7Pt, 160 cycles, (c) Ni50Al14PtZr, 120 cycles.

The interface between the bond coat and top coat is critical for understanding TBC lifetimes. Short lifetimes can result if this interface is not sufficiently rough or is not sufficiently clean. At the elevated test temperature, a protective alumina scale grows at this interface. This alumina is commonly referred to as the "thermally grown oxide," or TGO, to distinguish it from the ceramic top coat. It is well known that reactive element additions (e.g., $\mathrm{Hf}, \mathrm{Zr}$ or $\mathrm{Y}$ ) to monolithic NiAl alloys increases the adherence of the alumina scale to the substrate [7]. Poorly adherent scales typically spall from the 


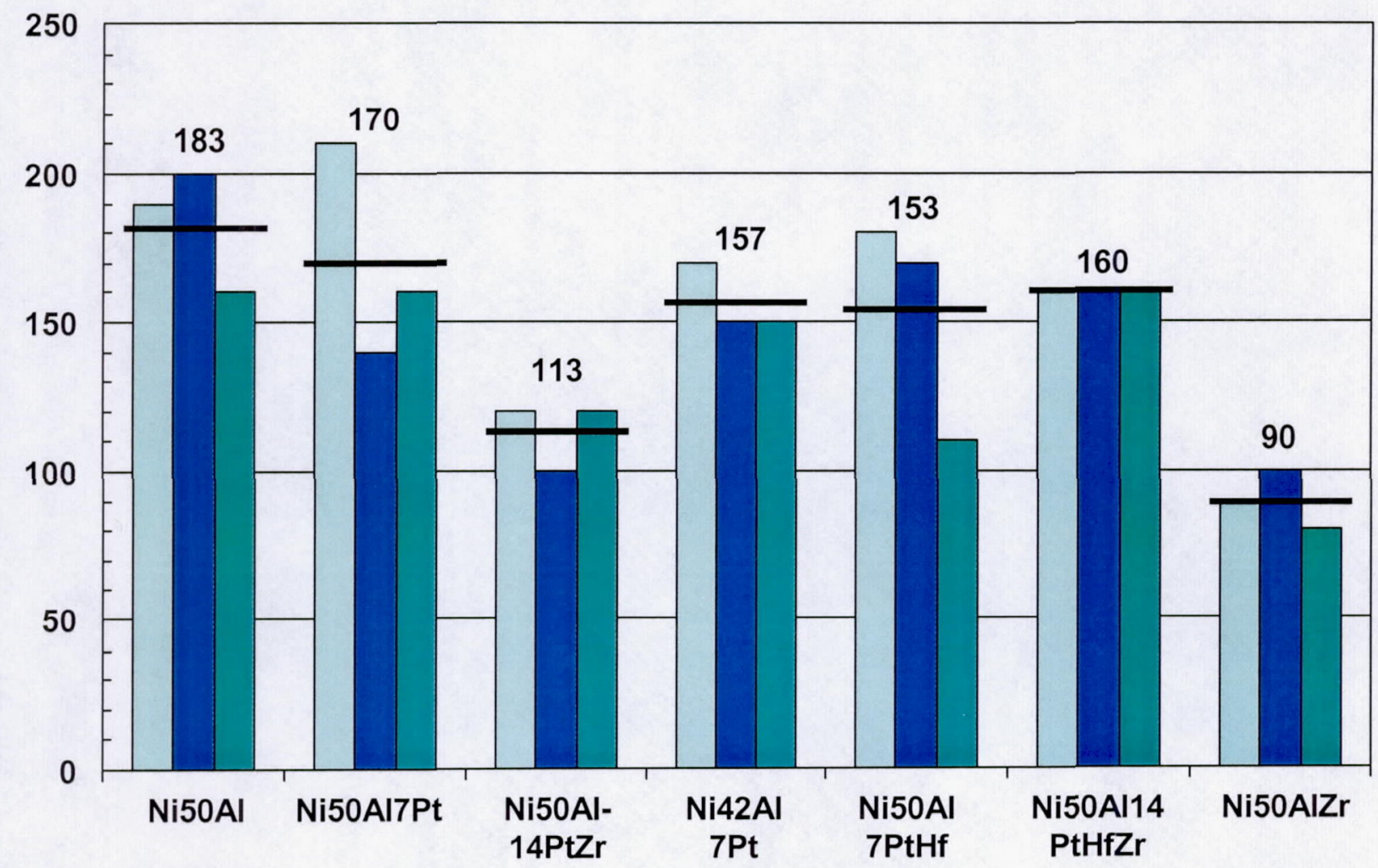

Figure 2 Number of cycles to failure (TBC lifetime). The number above each set of bars and the dark line for each composition indicate the average for the three samples.

surface during thermal cycling exposing easily recognized regions of bare metal [6]. This interface on samples of each bond coat was examined after testing by SEM.

The use of both secondary electron imaging (SEI) and backscatter electron imaging (BSE) with the SEM clearly delineates the 8YSZ top coat from the oxides which grow on the surface of the bond coat. The extensive top coat delamination allowed both surfaces of the bond coat/top coat interface to be examined. A typical view of the bond coat surface is shown in Fig 3. The dark regions in the BSE image $(b, d)$ are $\mathrm{Al}_{2} \mathrm{O}_{3}$ while the bright regions in the same image are 8YSZ. It is common for the alumina scale to show poor adherence to binary $\mathrm{NiAl}$, generally showing significant spalling of the oxide and exposing numerous regions of bare NiAl. However, close examination of the exposed alumina scale did not reveal any spalling to the bare NiAl bond coat. Figs $3 \mathrm{c}, \mathrm{d}$ show magnified views of the TGO alumina. Fig $3 c$ shows transgranular fracture through the alumina scale which indicates strong bonding at both the bond coat/alumina interface and the alumina/top coat interface. Plasma spraying the ceramic $8 \mathrm{YSZ}$ top coat results in a "splat" microstructure as the molten droplets impact the surface and solidify. As the top coat delaminates during thermal cycling, it is common for the fracture path to follow these "splat boundaries." Figs 3e,f show portions of the 8YSZ top coat attached to the bond coat surface. The smoothness of the surfaces indicates that the fracture path did follow many of the splat boundaries in this region. A fractured 8YSZ splat is shown in Fig $3 \mathrm{f}$ where the columnar solidification structure is evident.

The amount of fracture through the 8YSZ top coat or the alumina TGO, or at either the inner or outer alumina interface, indicates the strength and toughness of the bond coat/top coat interface. Significant amounts of $8 \mathrm{YSZ}$ adhering to the bond coat and/or large amounts of fractured alumina indicate a strong bond coat/top coat interface. The dark oxide shown in the BSE images in Fig 4 are primarily 

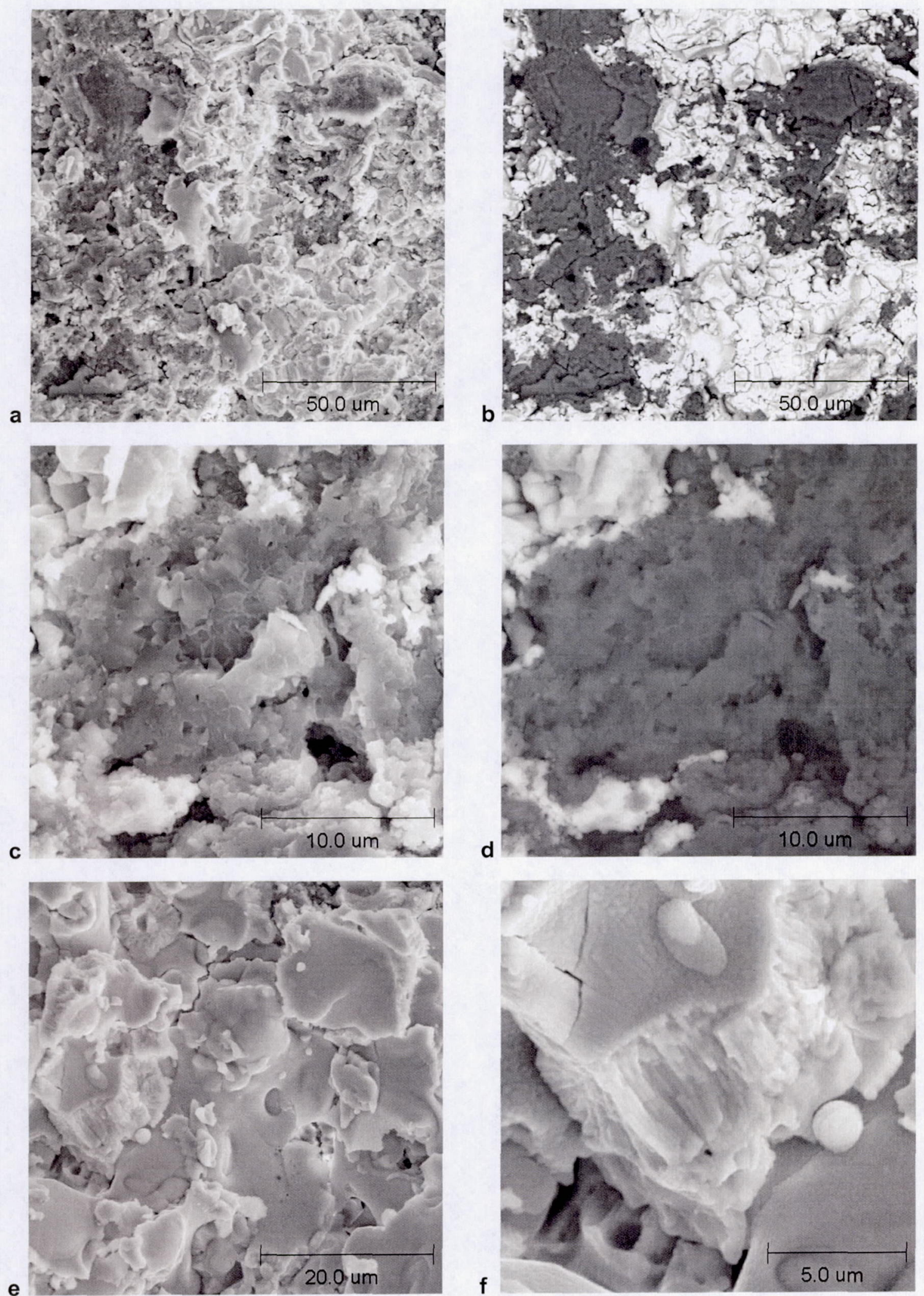

Figure 3 SEM micrographs of the bond coat surface of the Ni50Al bond coat after 160 cycles $(\mathrm{a}, \mathrm{c}, \mathrm{e}, \mathrm{f}) \mathrm{SEI},(\mathrm{b}, \mathrm{d}) \mathrm{BSE}$ image. The BSE images in b,d are of the same regions as a,c.

alumina. The images were segmented by brightness to determine the area fraction of the exposed alumina. A minimum of eight random regions across the sample surface were measured. The amount of exposed alumina on the bond coat surface was approximately $28 \%$. The amount of alumina 


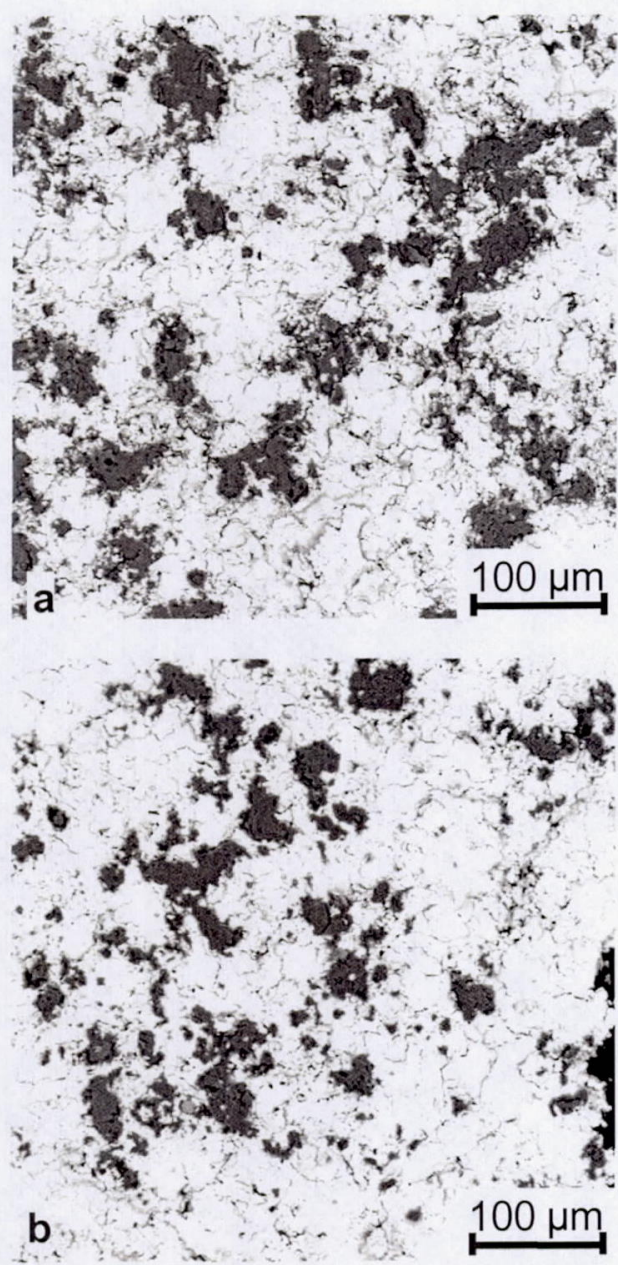

Figure 4 BSE micrographs of the (a) bond coat surface and (b) underside of the top coat on the Ni50Al bond coat after 160 cycles.

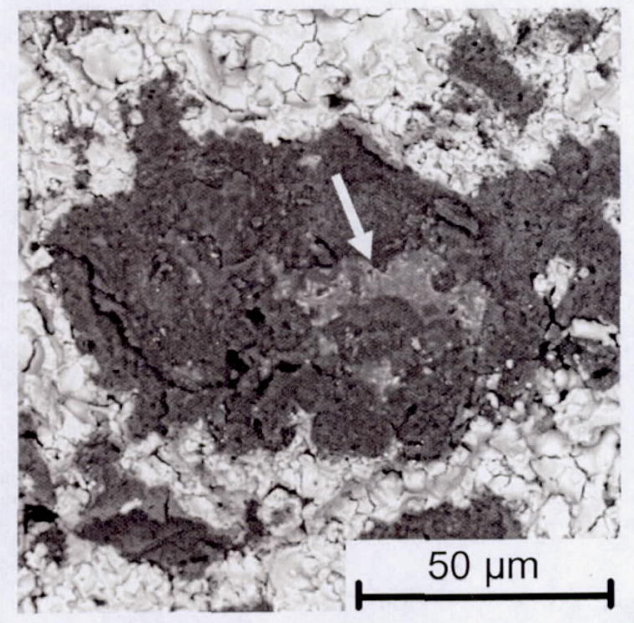

Figure 5 BSE image of the bond coat surface on the Ni50A114PtZr coating after 120 cycles. The arrow indicates a region of exposed bond coat. attached to the underside of the top coat was 16\% (standard deviation for both measurements was less than $\pm 2.5 \%$ ). The difference in the area fractions $(12 \%)$ suggests the amount that the fracture path traveled between the alumina TGO and the $8 Y S Z$ top coat. In comparison, the amount of exposed alumina on the Ni50A114PtZr bond coat (120 cycles) was $21 \%$ and the amount attached to the underside of the top coat was $13 \%$. The lower values suggest that more of the fracture occurred in the $8 \mathrm{YSZ}$ top coat, indicating a stronger bond coat/top coat interface in agreement with previous findings of increased adherence with small reactive element additions [7]. A closer examination of the bond coat surface on this sample did reveal small regions of exposed bond coat (or recently exposed with a thin, new growth of alumina) indicating some regions of decreased alumina/bond coat adherence (Fig 5). Surprisingly, no exposed bond coat was observed on the binary Ni50Al coating.

Notable differences were observed in the polished cross sections of the Ni50Al and Ni50All4PtZr coatings. In the Ni50Al14PtZr coating, the TGO alumina appeared much thicker and there were numerous oxide stringers growing inward from the TGO alumina into the coating (Fig 6). The oxide stringers are typical of bond coat alloys which contain more than an optimal amount of reactive element addition, such as Hf, $\mathrm{Y}$ or $\mathrm{Zr}$ [8]. It has been suggested that these oxide stringers, by growing into the bond coat, could act as a graded region transitioning the thermal expansion from the ceramic top coat to the metallic bond coat. However, there appears to be no benefit in TBC lifetimes due to this "graded" region. Although the fracture surfaces on the Ni50Al14PtZr coating indicated that the addition of $\mathrm{Zr}$ increased adherence at the bond coat/top coat interface, this benefit is likely more than offset by the thicker alumina scale resulting in the shorter lifetime for this coating in comparison to Ni50Al.

\section{Summary and Conclusions}

The addition of $\mathrm{Pt}$ alone at levels of $7 \%$ and $14 \%$ to $\mathrm{Ni}-50 \mathrm{Al}$ bond coats did not show a benefit to TBC lifetimes. Surprisingly, the addition of $\mathrm{Zr}$ to binary Ni-50Al or Ni-50Al14Pt decreased TBC lifetimes from that of binary Ni50Al. Examination of fracture surfaces indicated increased adherence in the bond coat containing the highest $\mathrm{Zr}$ concentration. However, microstructural examination of polished cross sections of this coating showed significant oxide stringer growth as well as a thicker alumina scale which likely contributed to the shorter lifetimes. 

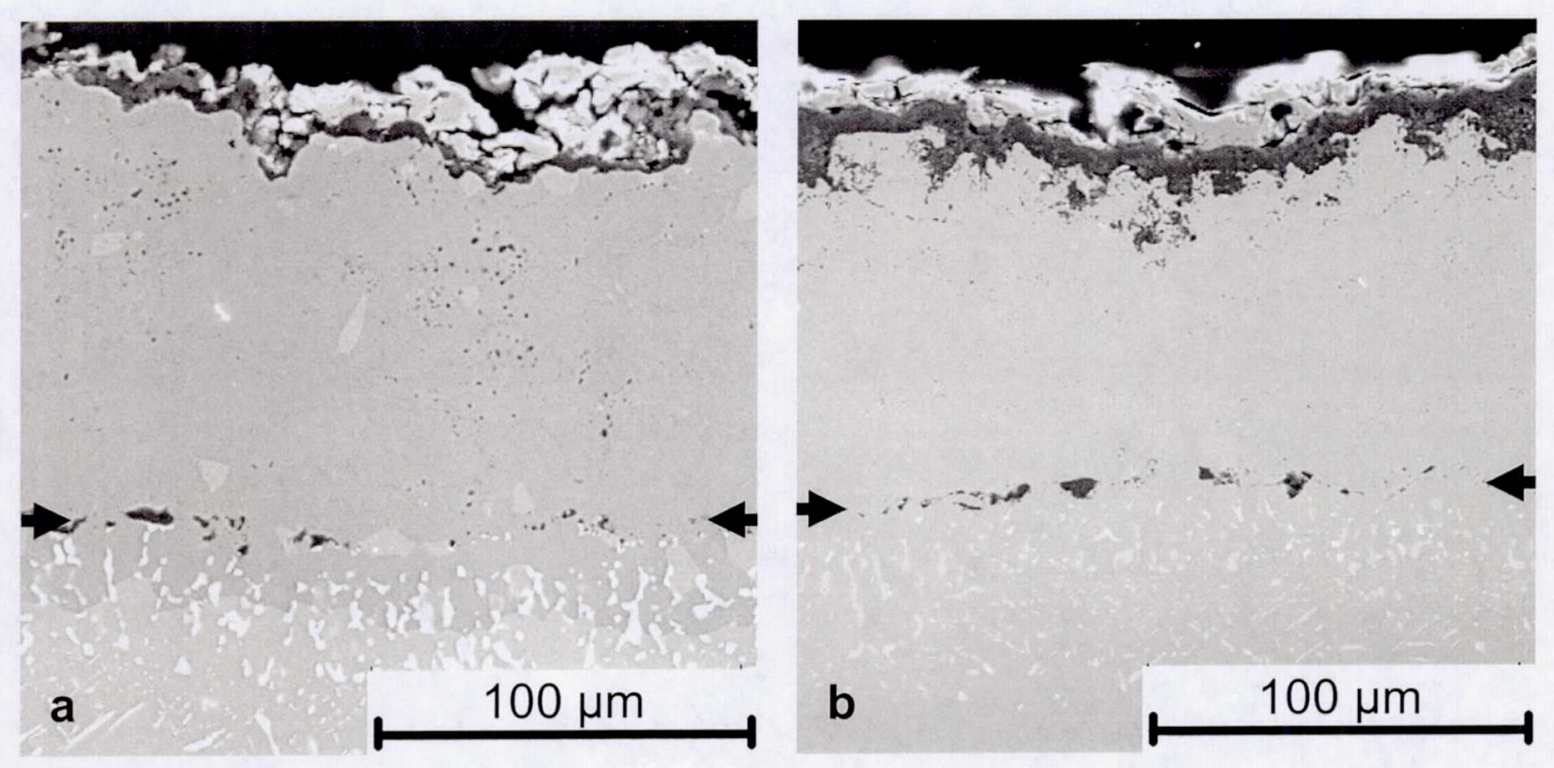

Figure 6 SEM micrographs of the (a) Ni50Al bond coat after 190 cycles and (b) the Ni50A114PtZr bond coat after 120 cycles. Arrows indicate the original substrate interface.

\section{Acknowledgements}

This work was performed under sponsorship of the Space Transportation and Propulsion Office, Propulsion Research \& Technology of the Advanced Space Transportation Program at the NASA Glenn Research Center.

\section{References}

[1] J.T. Demasi-Marcin and D.K. Gupta, Surface and Coatings Technol., 68/69 (1994), p 1.

[2] D. Zhu and R.A. Miller, MRS Bulletin, 27 (2000), p. 43.

[3] A. Maricocchi, A. Bartz, and D.J. Wortman, "PVD TBC Experience on GE Aircraft Engines," in Proceedings 1995 Thermal Barrier Workshop, W.J. Brindley, ed., (NASA CP 3312, Washington, DC, 1995), p. 79.

[4] P.C. Patnaik, R. Thamburaj and T.S. Sudarshan, "Formation and Behavior of Platinum Aluminide Coatings on Nickel-Base Superalloys," in Surface Modification Technologies III, T.S. Sudarshan, D.G. Bhat, eds, TMS, Warrendale, (1990) 759.

[5] Y. Zhang, W.Y. Lee, J.A. Haynes I.G Wright, B.A. Pint, K.M. Cooley, and P.K. Liaw, Metal. Mater. Trans., 30A (1999), p. 2679.

[6] J.A. Nesbitt, B. Nagaraj and J. Williams "Effect of Hf Additions to Pt Aluminide Bond Coats on EB-PVD TBC Life," Elevated Temperature Coatings: Science and Technology IV, ed. by N. B. Dahotre, J. M. Hampikian and J.E. Morral, The Minerals, Metals \& Materials Society, Warrendale, PA, 2001, pp. 79-92.

[7] B.A. Pint, Oxid. Met., 45 (1996), p. 1.

[8] G. Fisher, P.K. Datta, J.S. Burnell-Gray, W.Y. Chan, J.C. Soares, Surf. Coat. Technol., 110 (1998), p 24. 